\title{
Modelling the impact of microbial contamination of fuel filtration efficiency
}

In this paper the concept of filtration and the problem of microbial contamination occurring in the fuels and oils was presented. Then the factors influencing the growth of bacteria in petroleum products were described in detail. In the next part of the article modeling of the impact of fuel microbial contamination on filtration efficiency was performed. The modeling presented in the article is an example showing how undesirable phenomenon is the microbial contamination and how pollution affects the other elements of the entire system. As part of the modeling, numerical model of filtration with the solution was presented. Then analysis results on the basis of the impurities concentration characteristics in the fuel as a function of the fouling thickness in the partition of the filter is performed. The development of impurities was divided into three stages. In the article for one case the trend line was presented. The article was completed conclusions.

Key words: modeling, filtration, microorganisms, petroleum products, fuel system, oil system

\section{Introduction}

Filtration of diesel or lubricating oil consists in the separation of suspended particles, i.e. impurities, through the filter surface from a flow of diesel or lubricating oil. These impurities can be of very different sizes, and therefore the purification process itself is most often a complex process utilizing various physical phenomena. Physical phenomena that are most commonly used in filtration processes include: diffusion, barrier, sieve and electrostatic effects. However, in the filtering process may be involved, inter alia, gravitation, inertia, centrifugal and electrostatic interaction [5].

In the operation of internal combustion engines, the continuous filtration process, both diesel and lubricant, is extremely important. This is due to the fact that even in a properly operated piston engine, various types of pollution arise due to the deterioration of its technical condition. The deterioration of this condition is primarily due to all kinds of mechanical and chemical pollution. Out of all the various pollutants which different ways from the outside get into the engine and subassemblies of its equipment Various contaminants from different directions come from outside to the engine and subassemblies of its accessories or are formed inside the cylinders. The most harmful are the impurities contained in the fuel and the engine oil that is circulating in the engine lubrication circuit. Contamination of fuels and lubricating oils are all solid particles, water and dissolved chemicals (e.g. sulfur) that cause corrosion or undesired components (e.g. organic substances with high viscosity or gelatin content, etc.). The most harmful pollutants are mechanical impurities, and therefore mostly fine and hard particles of mineral substances of different graininess. Such impurities are partly a natural remnant of petrochemical processes, and partly pass to fuels and oils during distribution (transport, storage and transfer). The harmfulness of mechanical impurities in petroleum products results mainly from their hardness and compression resistance. Theoretically, all solids are classified as harmful, which in any way can mechanically affect for parts rinsed by fuel or exhaust [10].

Highly undesirable impurities of the diesel engine fuel are even small amounts of water that easily penetrates to the tank from the environment - most often in the form of water vapor, condensing on their walls due to lowering of temperature. Water due to much higher specific gravity, compared to diesel, collects in the lowest places inside pipelines and subassemblies of the fuel system. It often seriously interferes with their operation. As the ambient temperature drops even slightly below $0^{\circ} \mathrm{C}$, the water in the fuel easily freezes. It then transforms into fine ice needles, which blinding the passageways and passages of fuel system components interferes with the power supply of the engine, and often precludes its operation [5, 11].

\section{The problem of microbial contamination}

In petroleum products is a major problem microbial contamination, which includes both fuel for automobiles, aviation, and marine, motor and transformer oils and lubricants and oil emulsions. As the industry and automotive industry expanded, including aviation and ships, the problem of microbial contamination has been found to be still current and becoming more widespread. Research has shown that living organisms of microorganisms can lead to work disruption and even damage to car engines, aircraft or ships $[1,4]$.

The increase in microbial contamination of fuels and oils can be caused by a number of factors, including: changes in fuel sources and their quality, increased use of fuel additives that can provide compounds for microbial growth, and changes in fuel management and storage. The presence of microorganisms in the system can cause:

- production of corrosive compounds, causing the destruction of tanks, and thus an increase in the amount of mechanical impurities,

- adverse changes in physicochemical properties due to decomposition of hydrocarbons and additives, resulting in a decrease in chemical and thermal stability,

- production of surfactants,

- formation of sediment and biological membranes on the walls of tanks and ducts that contaminate the product after detaching from the substrate,

- clogging of filters and wires during operation.

Fuel of good quality must be clear and transparent. Growth of microorganisms can often contribute to its cloudiness and darkening. The most obvious and easy to 
understand consequence of microbial activity is the formation of sediments visible as solids, which are a mixture of living and dead cells and inorganic by-products [2, 8].

\section{The impact of microbial contamination of fuel filtration efficiency}

\subsection{Concept of modeling}

One of the methods of testing the dynamic properties of a system is to conduct an experiment directly on the system. In many cases, it is impossible to perform an experiment on a system, for technological reasons, or for the cost of an experiment. An important factor is the duration of the tests, which can be very long and take several years (for example, in the fatigue test) or very short, on the order of fractions of seconds (transients in electrical systems). It is difficult to record the courses of a individual values [6].

Another approach to the problem of testing properties of the system is to build a system model and testing the model. A system model is a representation of a system using mathematical relationships (abstract form of a system) or in a physical form (a layout model) that depicts, usually with some simplification, the properties of the system.

Mathematical model (abstract) is a collection of mathematical relations, based on which one can predict the behavior of a system. The mathematical model of the continuous system is usually the differential equation describing the operation of the system. Mathematical models are most often implemented by means of digital machines and electronic analogue machines. The main advantage of digital modeling is the ability to save the model and its parameters in the program form. This makes it possible to perform model tests flexibly.

Mathematical modeling provides the ability to quickly and accurately investigate courses in the most complex systems, with different combinations of parameters and with different kinds of extortion. One of the basic aims of modeling is to use a model in an adaptive system, which allows to select the structure and parameters of this model most similar to the behavior of the real system. The basic element of programming a digital machine (mathematical modeling) is to create an operational schema of the studied system. Because the operation of the continuous system is most often described by differential equations, the modeling of the system consists in creating an operating scheme for the differential equation or system of equations. The presented system is investigated by means of a process simulation method, using various methods for solving differential equations [9].

In the article, modeling the influence of pollutants on the efficiency of filtration using a numerical algorithm was presented.

\subsection{Mathematical numerical filtration}

In the process of filtering contaminants balance equation connects the change dynamics in the degree of contaminants in the fluid filtered with the change dynamics in the concentration contaminants accumulated in the porous baffle. On the basis of change in concentration of contaminants in the filtered liquid conducted to the desired depth baffle can be estimated concentration change deposits accumulated in the baffle of the filter at that depth. The con- centration of the contaminants in the filtered liquid is expressed as a weight by volume. The mass balance equation, in the case of constant speed in a cross-section of the filtrating barrier and the one-dimensional flow, has the following form:

$$
\frac{\partial \sigma(\mathrm{t}, \mathrm{d})}{\partial \mathrm{t}}+\varepsilon_{\mathrm{o}} \frac{\partial \mathrm{C}(\mathrm{t}, \mathrm{d})}{\partial \mathrm{t}}+\mathrm{v} \frac{\partial \mathrm{C}(\mathrm{t}, \mathrm{d})}{\partial \mathrm{d}}=\mathrm{D} \frac{\partial^{2} \mathrm{C}(\mathrm{t}, \mathrm{d})}{\partial \mathrm{d}^{2}}
$$

where: $\sigma(t, d)$ - mass concentration of impurities in the filter baffle at time "t"at a depth "d" $\mathrm{g} / \mathrm{m}^{3} ; \mathrm{C}(\mathrm{t}, \mathrm{d})$ - concentration of impurities in the liquid at time " $t$ "at a depth "d" $\mathrm{g} / \mathrm{m}^{3}, \varepsilon_{\mathrm{o}}$ - porosity of the barrier filter, D - dispersion coefficients, $\mathrm{m}^{2} / \mathrm{s}$.

Assuming that the second component of equation (1) equals zero and ignoring dispersion the simplest form of mass balance equations is obtained [3]:

$$
\mathrm{V}\left(\frac{\partial \mathrm{C}(\mathrm{t}, \mathrm{d})}{\partial \mathrm{d}}\right)+\left(\frac{\partial \sigma(\mathrm{t}, \mathrm{d})}{\partial \mathrm{t}}\right)=0
$$

The kinetic of the filtration process can be described in different ways. The simplest way to describe the kinetic of removal of contaminants from the filtered fluid as it passes through the barrier using the concept of filtration coefficient, determining the effectiveness of contaminant removal. One of the forms the kinetic equation is the change in the concentration of impurities in the filtered liquid per unit depth of the baffle proportional to the concentration. Kinetic equation is as follows:

$$
\mathrm{a} \frac{\partial \mathrm{C}(\mathrm{t}, \mathrm{d})}{\partial \mathrm{d}}=-\lambda \mathrm{C}(\mathrm{t}, \mathrm{d})
$$

where: $\lambda$ - filtration coefficient, $1 / \mathrm{m}$.

Filtration coefficient is a measure of the efficiency of the filter and is dependent on parameters such as the type and diameter of pores, filtration speed, physico-chemical properties of the liquid filtered and concentration of the contaminants retained in the baffle. The function has the following form:

$$
\lambda=\lambda\left(\lambda_{\mathrm{o}}, \sigma(\mathrm{t}, \mathrm{d}), \mathrm{v}(\mathrm{t})\right)
$$

expressing filtration coefficient by its initial value, where $v(t)$ is the filtration speed in $\mathrm{m} / \mathrm{h}$.

The most popular model is in the form [3]:

$$
\lambda=\lambda_{\mathrm{o}}\left(1+\frac{\beta \sigma(\mathrm{t}, \mathrm{d})}{\varepsilon_{\mathrm{o}}}\right)^{\mathrm{x}}\left(1-\frac{\sigma(\mathrm{t}, \mathrm{d})}{\varepsilon_{\mathrm{o}}}\right)^{\mathrm{y}}\left(1-\frac{\sigma(\mathrm{t}, \mathrm{d})}{\sigma_{\mathrm{u}}(\mathrm{v})}\right)^{\mathrm{z}(\mathrm{v})}
$$

where $\sigma_{\mathrm{u}}$ is the contractual concentration of pollutants for which $\lambda=0$.

In this model, three types of factors that influence the value of filtration were included, and besides, its value depends on the exponents of power series of $\mathrm{x}, \mathrm{y}, \mathrm{z}$, determined experimentally.

The first factor in parentheses included an increase in the specific surface area of the baffle filter, due to the contaminants deposited on the baffle. The second one takes into account the reduction of the porosity of the barrier at the time of filtration as compared to its initial porosity due to the deposition of contaminants in the pores of the baffle. The third factor takes into account the increase in the average filtration speed resulting from the reduction of the cross-section the pores by the deposition of impurities on 
the baffle. In the description of the filtration process, assuming additivity of the pressure loss when flowing through the clean filtering barrier and the pressure losses resulting from the accumulation of contaminants in the baffle, the pressure equation is of the form [3]:

$$
\frac{\partial \mathrm{p}(\mathrm{t}, \mathrm{d})}{\partial \mathrm{d}}=1-\frac{\mathrm{K}_{\mathrm{o}} \mu \mathrm{v}\left(1-\varepsilon_{\mathrm{o}}\right)^{2}}{\rho \mathrm{g} \varepsilon_{\mathrm{o}}^{3} \psi^{2} \mathrm{~d}_{\mathrm{s}}^{2}}-\mathrm{b}_{1}\left(\frac{6\left(1-\varepsilon_{\mathrm{o}}\right)}{\psi \mathrm{d}_{\mathrm{s}}}\right)^{0,9} \mathrm{v}^{0,4} \sigma_{\mathrm{o}}(\mathrm{t}, \mathrm{d})
$$

where: $p(t, d)$ - the pressure in the filter baffle at the time " $\mathrm{t}$ " at the depth "d" from the boundary condition $\mathrm{h}(\mathrm{t}, 0)=$ $h_{o}$, where $h_{o}$ is the pressure on the surface of the baffle, $\mathrm{mH}_{2} \mathrm{O}, \mathrm{K}_{\mathrm{o}}-$ Kozeny constant, $\rho$ - specific mass of the liquid, $\mathrm{g} / \mathrm{m}^{3}, \mu$ - the coefficient of dynamic viscosity of the liquid, $\mathrm{g} / \mathrm{m} \cdot \mathrm{s}, \psi-$ the pores shape factor, ds - effective diameter of the pores in the filter baffle, mm, $\sigma o(t, d)-$ volume concentration contaminants, $\mathrm{g} / \mathrm{m}^{3}, \mathrm{~g}$ - acceleration of gravity, $\mathrm{m} / \mathrm{s}^{2}$.

\section{Numerical solution of equations of filtration and analysis of simulation results}

Model of the filtration process is a set of three differential equations with partial derivatives, preset initial conditions and boundary, defining function $\mathrm{C}(\mathrm{t}, \mathrm{d}), \sigma(\mathrm{t}, \mathrm{d})$ and $\mathrm{h}(\mathrm{t}, \mathrm{d})$, whose arguments are continuous. For numerical solution of the model equations, as well as to identify its parameters, it is necessary discretization arguments occurring in these functions. According to the shape of the area where certain functions are considered, discretization on a uniform rectangular grid was adopted. The row number of the array corresponds to a fixed point in time, and the column number corresponds to a fixed depth in the baffle filter. The discrete version of the model equations was adopted the simplest - differential - approximation of partial derivatives occurring in these equations by difference quotients:

$$
\begin{gathered}
\frac{\mathrm{C}(\mathrm{k}, \mathrm{i})-\mathrm{C}(\mathrm{k}, \mathrm{i}-1)}{\Delta \mathrm{L}}=-\lambda(\sigma(\mathrm{k}, \mathrm{i})) \mathrm{C}(\mathrm{k}, \mathrm{i}), \\
\frac{\sigma(\mathrm{k}, \mathrm{i})-\sigma(\mathrm{k}-1, \mathrm{i})}{\Delta \mathrm{T}}=\mathrm{v}(\mathrm{k}-1) \frac{\mathrm{C}(\mathrm{k}-1, \mathrm{i}) \mathrm{C}(\mathrm{k}-1, \mathrm{i}-1)}{\Delta \mathrm{L}} \\
\frac{\mathrm{p}(\mathrm{k}, \mathrm{i})-\mathrm{p}(\mathrm{k}, \mathrm{i}-1)}{\Delta \mathrm{L}}=\mathrm{k}_{1} \sigma(\mathrm{k}, \mathrm{i})+\mathrm{k}_{2},
\end{gathered}
$$

Solving equations in the variables of the so-called more discreet argument is obtained:

$$
\mathrm{C}(\mathrm{k}, \mathrm{i})=\frac{\mathrm{C}(\mathrm{k}, \mathrm{i}-1)}{1+\Delta \mathrm{L} \lambda(\sigma(\mathrm{k}, \mathrm{i}))}
$$

$$
\sigma(\mathrm{k}, \mathrm{i})=\sigma(\mathrm{k}-1, \mathrm{i})+\Delta \operatorname{tv}(\mathrm{k}-1) \lambda(\sigma(\mathrm{k}-1, \mathrm{i})) \mathrm{C}(\mathrm{k}-
$$
$1, \mathrm{i})$,

$$
\mathrm{p}(\mathrm{k}, \mathrm{i})=\mathrm{p}(\mathrm{k}, \mathrm{i}-1)+\Delta \mathrm{Lk}_{1}(\sigma(\mathrm{k}, \mathrm{i}))+\mathrm{k}_{2},
$$

For example, in the article analysis of the results for the concentration of contaminants in the fuel as a function of the thickness of deposition on baffle filter was made.

Marine diesel oils are purified in stages, which includes gravity sedimentation, filtration and centrifugation. Fuel, before the filtration, is stored in settling tanks. As a result of a long period storage of fuel, occurs the growth of microorganisms and consequently the level of microbial contamination of the fuel increases.
Depending on the amount of microorganisms in the fuel, there are three stages in the development of contamination $[4,8]$ :

- no contamination, low,

- growing, medium,

- very tall.

Progressive microbiological contamination affects the sedimentation contaminants on the filter baffle. If dirt particles are smaller than the pore diameter to penetrate with the fuel to the engine fuel system, causing rapid wear and, consequently, its malfunction. The simulation results of the filtration process in graph function $\mathrm{C}(\mathrm{d})$ were shown in Figure 1. Analyzing the form of the function $\mathrm{C}(\mathrm{d})$ it can be noted that at the beginning of the process linear increase in function has performed. The concentration contaminants was about $3 \cdot 10^{-6} \mathrm{~g} / \mathrm{ml}$ at a depth $0.5 \mathrm{~cm}$. Then this growth had exponential course and concentrations of pollutants reached the level about $4 \cdot 10^{-5} \mathrm{~g} / \mathrm{ml}$, the last stage again had linear course and concentration contaminants at a depth of $1.5 \mathrm{~cm}$ was around $4.5 \cdot 10^{-5} \mathrm{~g} / \mathrm{ml}$. Presented course may be related to the development of micro-organisms. At the beginning of a slight increase, because the level of microbial contamination is very low. In the second stage there is an increase of impurities, which results in faster deposition of the deeper layers of the filter increasing concentrations. In the last stage of the level of pollution it is very high, there is a blocking filter, which is contaminated with whole. Despite the development of contaminants, course characteristic is linear, because due to increasing contaminants the filtration process slowly stops, which will involve increasing pressure drop across the filter. In order to prevent to interrupt flow fuel, the filter should be cleaned or replaced. Therefore, to the fuel are added additives, including biocides, in practice rarely achieves the case.

Unfortunately biocide are compounds, synthetic or natural origin to combat harmful organisms, which unfortunately also destroy beneficial organisms and cause adverse changes in the composition of microorganisms. Despite a number of benefits arising from the use of biocides, it is now a strong tendency to limit their use [7]. They are caused by the fear of the harmful effects of highly concentrated substances on the environment. There is therefore a need to find new methods for to combat of microbial contamination, which will not destroy the useful microorganisms and they will be environmentally friendly.

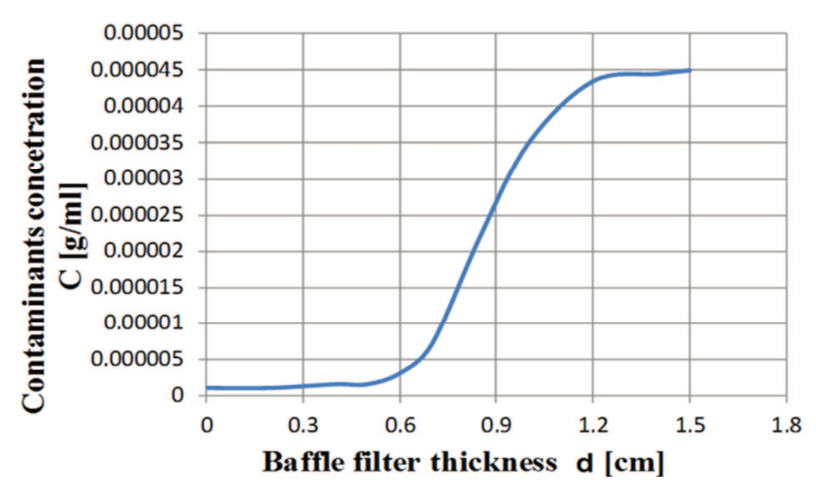

Fig. 1. Course of characteristic as a function of the concentration of contaminants in the deposition thickness of baffle filter 


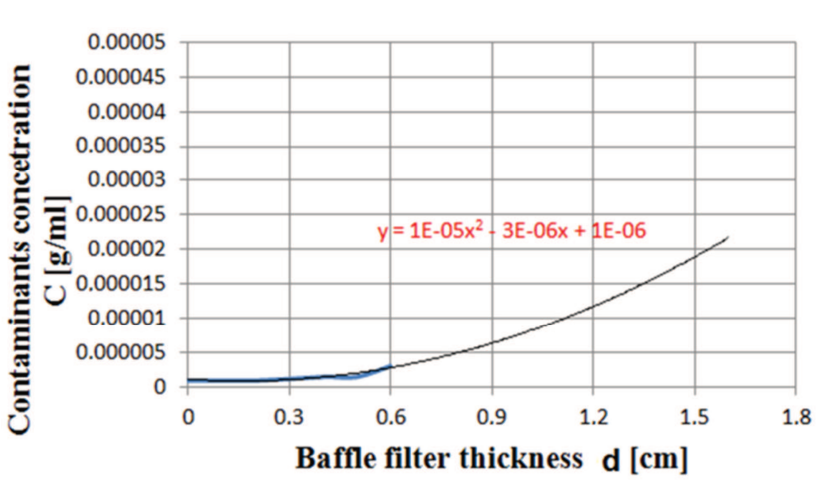

Fig. 2. Course of characteristic in the first stage of contaminants development together with the trend line and the development forecast after application of the countering microorganisms

Besides, for each stage of the filtration process trendline and the equation that describes it has been designated. They were also forecast, how would run characteristics, if at any stage the process of increasing contaminants would be stopped.

Forecasts show that the process of filter contamination is slower and contamination after the first stage is $2 \cdot 10^{-5}$ $\mathrm{g} / \mathrm{ml}$, in comparison with $4.5 \cdot 10^{-5}$ with the process without the use of additives, which is shown in Fig. 2.

\section{Conclusions}

1. With the development of industry and the wider automotive industry, it turned out that the problem of microbial contamination is still valid and it becomes more commonplace. Research showed that the activity of microbial life can lead to interference and even damage engines of vehicles, aircraft or ship.

2. Progressive microbial contamination has a significant impact, for example on the status of all fuel and lubricant systems components, causing the corrosion. Growing contamination cause excessive clogging of the filter barrier, resulting in a faster wear of the filter. If dirt particles are smaller than the pore diameter to penetrate with the fuel to the engine fuel system, causing rapid wear and, consequently, its malfunction

3. The development of the filtration model allows to simulate the effect of various pollutants on the efficiency of diesel oil filtration. In addition, this model allows you to check the performance of various additives in oils and to determine the potential for reducing the adverse effect of microorganisms on petroleum products.

4. It is necessary to develop effective methods for combating microbial contamination of fuels and oils, taking into account both the technical aspects and the specifics of the processes occurring in the fuel and lubricating systems by the means which will be environmentally friendly.

\section{Bibliography}

[1] DUDA, A. Problemy skażenia mikrobiologicznego w dystrybucji i magazynowania paliw naftowych. Nafta-Gaz. 2002, 58(3), 160-167.

[2] GAYLARDE, C.C., BENTO, F., KELlEY J. Microbial contamination of stored hydrocarbon fuels and its control. Revista de Microbiologia. 1999, 30.

[3] IVES, K.I. Mathematical models of deep-bed filtration. Basis of Filtration Nordhoff International. 1975 Leyden.

[4] JANDA, K. Mikrobiologiczne skażenie paliw. Postepy mikrobiologii. 2005, 44, 157-169.

[5] KAISER, K. Filtry i filtracja (2). Filtracja i mechanizm filtracji. Technika Chłodnicza i Klimatyzacyjna. 2007, 5, 202-204.

[6] KAULA, R. Podstawy automatyki. Wydawnictwo Politechniki Ślaskiej. 2005.

Rafał Krakowski, DEng. - Faculty of Marine Engineering at Gdynia Maritime University.

e-mail: R.Krakowski@am.gdynia.pl
[7] KLOFUTAR, B., GOŁĄB, J. Microorganisms in diesel and in biodiesel fuels. Acta Chimica Slovenica. 2007, 54(4), 744-748.

[8] LASOCKI, J., KARWOWSKA, E. Wpływ mikroorganizmów bytujących w środowisku oleju napędowego i biodiesla na układ paliwowy pojazdów napędzanych silnikami o zapłonie samoczynnym. Archiwum Motoryzacji. 2010, 3, 167-183.

[9] MARCINKOWSKI, L. Numeryczne rozwiązywanie równań różniczkowych. Wydawnictwo Politechniki Warszawskiej. 2011.

[10] NIEWCZAS, A., WRONA J., WRONA R. Zanieczyszczenia oleju smarującego oraz ich wpływ na trwałość silnika spalinowego. Autobusy: technika, eksploatacja, systemy transportowe, 2010, 11(6), 1-5.

[11] SITNIK, L. Magnetyczne wspomagana filtracja oleju silnikowego. Archiwum Motoryzacji. 2009, 1, 11-38. 